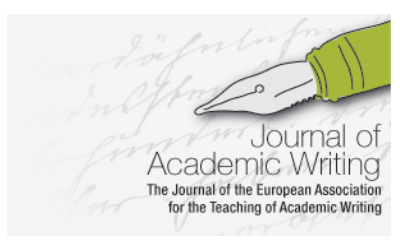

Journal of Academic Writing

Vol. 10 No 1 WINTER 2020, pages 171-179

https://doi.org/10.18552/joaw.v10i1.611

\title{
"I pictured my little sister when writing" - Teacher and Student Experiences with Training Audience Awareness in a Television Studies Seminar
}

\author{
Regina Leonie Schmidt \\ Justus Liebig University Giessen, Germany
}

\begin{abstract}
Training audience awareness is a significant but challenging task for teaching academic writing. To integrate the teaching of television studies with writing skills, I designed a BA seminar when working as a lecturer in the English department of a German university in 2015. I present my experience with and my students' evaluation of training audience awareness as part of this seminar. The evaluations confirmed students' increased awareness of the importance of incorporating audience-directed elements in writing, but indicated that the task had created obstacles, for example, regarding students' reading comprehension. I retrospectively analyze my teaching approach and discuss possible reasons for my students' success and difficulties with the writing assignment, and make suggestions for changes that may have better supported their learning process. I, therewith, aim to foster the integration of teaching writing within, across, and beyond disciplinary audiences in discipline-specific courses.
\end{abstract}

\section{Introduction}

Audience awareness has been considered a crucial skill to master for student writers in academia. The ability to react in writing towards general academic and discipline-specific audience expectations not only promises an effective communication of students with their discourse community but also raises hopes towards students "learning to be flexible writers," and to "be able to adapt to a variety of writing situations" (Beaufort, 2007, p. 15). This competence seems desirable for the variable research settings and disciplines students encounter during their academic careers, and it is believed to become even more significant once students' professional careers unfold after graduation.

Despite the significance of students' mastery of this skill, teaching audience awareness has been recognized as a challenging endeavor for writing instructors. This is due to theoretical considerations concerning the elusiveness of the term audience and the agreement among researchers that "[a]udience is... rarely a concrete reality in academic environments" (Hyland, 2001, p. 551). This notion is further complicated through the presence of a specific reader of students' written words in the form of the respective course instructor (see Park, 1982). In consequence of this complex setting, different approaches have developed which understand the audience of a text either to be a real-life addressee, or an imaginary construct invented and invoked by the author in writing, or which try to interrelate both (see Ede, 1984; Ede \& Lunsford, 1984; Reiff, 2002). Also, this complexity is mirrored in teaching practices. Writing trainers often tell their students not to write (exclusively) for their course instructors. However, students, during their school and academic careers, have become "experts" in "learning how to read us" (Pope-Ruark, 2011, p. 1) and in adjusting their writing accordingly. What writing instructors aim to raise awareness for, though, is that students are expected to address their scientific 
discourse community in addition to the course instructor and that this notion will influence their texts.

While being a challenge for writing instructors, teaching audience awareness can seem impossible to manage for lecturers who teach in the disciplines and often have little experience negotiating writing conventions with their students explicitly. I have gained experience in both roles: as a teacher of academic writing in English at the Writing Center of the Justus Liebig University Giessen, Germany, since 2018, and as a junior lecturer at the English Literature and Culture Department of that same university between 2013 and 2017. This text relates my students' and my own assessment of how I did and did not succeed in teaching audience awareness. Based on my students' evaluations, I perform a retrospective analysis of my teaching experience from my current perspective to discuss insights this has generated for me. The account is meant to empower lecturers in the disciplines who bravely continue to struggle with negotiating this complex topic with their students. Moreover, this experience might interest writing instructors who cooperate with faculty regarding the integration of academic writing in discipline-specific courses as it shows which concerns might arise for lecturers when teaching audience awareness.

\section{Context of the Teaching Experience}

I was teaching in the first-year introductory modules of the study programs in the English Literature department during the summer term of 2015. These modules are characterized by the heterogeneity of the students. Participants are L2 speakers of English from different academic backgrounds (literature and culture, linguistics, didactics/teaching, etc.), multiple academic levels, and with varied academic writing experiences. First-year students who have never written a term paper sit next to aspiring teachers in their final semester, ${ }^{1}$ and all of them need to be addressed regarding the module-specific demand to familiarize students with the basics of academic writing. Moreover, academic reading and writing skills are not systematically taught to students in the department.

To cater to the needs of rookie writers, I designed the course Scripted Entertainment: An Introduction to Television Series, which introduced students to the basics of media analysis and academic writing. Half of each session was devoted to familiarizing students with term paper writing, and participants had to complete several writing assignments in class and at home. At the end of the course, they had to hand in a term paper and a written evaluation of the writing training in order to receive credit. To support my writing-related work, the university's writing center sponsored a writing tutor, a student who offered regular office hours and provided feedback on some of the students' writing assignments.

One of the seminar sessions was devoted to audience-specific writing. My teaching goals were to raise audience awareness among the participants and to problematize the wide-spread notion of class instructors as the (only) addressees of students' texts. I familiarized students with a rhetorical approach to audiences in order to enhance the author-centered perspective with which they often approach the writing of academic texts. We talked about the rhetorical situatedness of texts, and the five elements rhetorical situations share, i.e. text, author, audience, purpose, and setting (Appendix 1, Slide 1). We discussed informative and persuasive author purposes in English literature writing (Appendix 1, Slide 2) to draw attention to the fact that texts in the field are mainly persuasive but that purposes also intertwine or vary between different textual sections. We discussed different audiences for students' texts to illustrate that they would need to address several audiences at the same time and persuade a discourse community of a point of view, rather than inform the course instructor about a state of

\footnotetext{
${ }^{1}$ The introductory courses are mandatory for all study programs the department offers but scheduled variedly. Some programs advise to take an introduction in the first year, others schedule participation for the second year. Moreover, courses offered by the department are not consecutive. Therefore, students are free to determine their schedule and, for reasons such as (dis-)interest in the study topics offered or temporal overlaps, often decide to take the introduction late in their studies.
} 
knowledge. The session concluded with how the aspects discussed influence writing and how to create an audience profile based on questions (Appendix 1, Slide 3).

Due to the heterogeneity of the group, I offered different options for the mandatory but ungraded writing assignment that students composed after the session, on which they received written feedback by my tutor. All students composed a summary of a text (Casey et al., 2002, pp. 71 76), and were asked to informally analyze their audience before starting to write, based on the discussions we had had in class. The students should choose between three different predefined audiences: an academic audience, an audience of pupils, and a professional audience of literary publishers (see Appendix 2). The text on which the assignment was based originated from a television studies reference book and I considered it suitable as it was only five pages long and introductory.

\section{Students' Evaluations of the Writing Assignment}

It was not until I read my students' evaluations ${ }^{2}$ at the end of term that I became aware that my writing assignment had caused problems for the participants. I received 36 evaluations, ${ }^{3}$ which the students had to compose by means of guiding questions, one of which asked them to reflect on a writing assignment of their choice. Despite the plethora of writing assignments, 14 of the 36 evaluations commented on the assignment described above.

Several students mentioned the assignment favorably. They stated that this had been the first time they had "actually thought about specific addressees for [their] texts" (student 1 ) when composing them. Moreover, the assignment seemed to have helped them to imagine the audience as a specific person within a specific scenario, possibly from their immediate surroundings, and this strategy enabled them to relate to these real-life audience embodiments. One student wrote: "I pictured my little sister when writing. This image made the writing assignment more accessible for me and facilitated writing the summary" (student 2). These comments indicate not only that the writing assignment had generated a basic awareness among some students that they were inevitably writing for an audience and that this (self-) conceptualization might impact on their texts in specific ways. They also indicate that imagining a reader raised awareness among the students that this strategy might grant them a new access to writing.

Furthermore, the writing assignment seemed to have motivated students to think about how to convey information to their audience, i.e. how much and what kind of information to include, the level of detail, how to organize information, and how to adapt the appropriate language, tone, and style:

I was using words and phrases that a grade eight pupil would probably not be familiar with. I study to become a teacher and now I realize the challenge of adapting my language to the audience I will encounter professionally. (student 3)

Despite possibly not being able to follow through in writing, the student mentions an increased awareness of the need for language-based changes regarding the audience and recognizes that this practice will be of relevance for her professional future.

There were just as many students who mentioned the writing assignment unfavorably, though. Several students admitted that they had had problems reading the text by Casey et al. One student wrote: "It was not the writing assignment as such I had difficulties with, but the text we

\footnotetext{
${ }^{2}$ All excerpts of students' texts derive from evaluations of students who permitted my usage of their evaluations for research purposes. Some evaluations were written in German; all translations from the German are by the author. Students' names were omitted.

3 Initially, 50 students enrolled in the course. The divergence between the number of enrollments and the number of evaluations is due to some students dropping the course, some completing the course with ungraded credit (i.e. without term paper/evaluation), and some deciding not to give permission for my usage of their evaluations.
} 
were supposed to summarize" (student 4). Diverse students criticized the text as "too comprehensive," "unstructured," "superficial," "full of mental leaps," "complex," "inaccessible," and "missing a guiding thread." Therefore, some also considered the 300-word limit of the writing assignment too low for a good summary (student 5 , student 6 ). While some participants argued that the perceived complexity of Casey et al. had also raised their awareness for the necessity to structure texts well (student 7 , student 8 ) and rated overcoming their difficulties as positive, some students seemed to feel that the text set them up for failure and made the task unnecessarily complicated.

\section{My Retrospective Assessment of the Teaching Experience}

After reading my students' evaluations, I felt disheartened regarding teaching audience awareness. It was disappointing that completing the assignment had been a frustrating experience for the students from which they took away that they had been "tricked" into working with a "bad" text. My teaching approach seemed so flawed that I excluded audience awareness entirely from my schedule the next time I offered an introductory course. From the perspective of the writing teacher I am now, I look at my experience differently than I did in 2015. Now, I am surprised how much this experience appears to have been a microcosm of what has been negotiated in writing research over the past decades. A prime example for this is my student's statement that she "pictured her little sister when writing." This plays right into Marilyn M. Cooper's (1986) hands who advocated for the introduction of "real readers" or "readers as social beings" (p. 373) into academic classrooms. My student's strategy indicates that, for her as for Cooper, writing therewith turns into an "essentially social activit[y]" (p. 366) rather than simply being a means to convey information. I find it important to bear this possibility of a concrete reader invocation in mind as it might facilitate students' access to writing for an audience. Moreover, this was the first clue I came across in research as to the notion that my teaching attempt might not have been entirely unsuccessful. This motivated me to look more closely at my students' self-reported experiences.

Despite this positive realization, I now see the nuances of the challenges of teaching audience awareness, for example regarding the conceptualization of writing assignments. I focused on conceptualizing an assignment which was challenging as well as requiring original work and provided a hands-on scenario of a real-life writing situation for different study programs. The summary seemed to me an educational core genre and I assumed that my students would be experts in writing it. Working as a writing instructor I now consider summary writing as posing a challenge to undergraduate students as it necessitates the selection of textual information whose higher or lower significance students often lack the confidence to judge. Moreover, students often perceive summaries as a particularly objective, static genre that does not need to be adjusted to an audience and assume that there is a single, correct way to write them. To me it was clear that an audience analysis would impact on how students provided information in their summaries, for example, the selection of information, its (re-)organization, and the language used to reproduce it. Some evaluations indicated that students partly realized this, too. However, I overlooked that to further my students' successful accomplishment of the task, it might have been beneficial if I had made clear by means of the discussion of different sample summaries of the same text written for different audiences, how an audience analysis might influence the way information is provided in this genre. On the other hand, more scaffolding would have been necessary to train the students in relation to the genre they were supposed to write in. If I had supported my students in mastering the genre step by step by scaffolding the work with the source text and the writing as such, possibly they would have struggled less.

I also have to question the approach I chose, i.e. relying on the performance of an audience analysis. According to Ede (1984), this technique works based on inferences made by writers about demographic features of their audience and seemingly corresponding "experiences, beliefs, and attitudes" (p. 140). It is often chosen as a starting point for teaching audience awareness as it provides "practical, concrete checklists and schemata" (p. 141). However, this technique encourages writers to generalize among audience members on the basis of demographic features and to allocate alleged group attitudes that derive from stereotypical social notions. In my current position, I noticed that when asked about what they think their 
academic audience values about texts, my undergraduate students often answer "big words" and that it takes time to understand that using pompous language is not a requirement of good research writing. Moreover, generalizing social groups seems counterintuitive when teaching English literature, a discipline that is highly concerned with training students to critically scrutinize the stereotypes they encounter in texts. These issues should be openly addressed and discussed with students when using this technique in teaching.

Audience profiling is also criticized for its "failure to distinguish between actual auditors, those who read or hear a discourse, and those auditors implied by a text" (Ede, 1984, p. 144). This causes a problematic reduction of the complexity of audiences, implying that there was only one audience that should be analyzed and addressed - in my case the audience specified in the assignment. Students have to negotiate the above mentioned gap between instructorreader and discourse-community audience in their academic texts, though. Therefore, writing research has called for teaching "more complex approaches" (Reiff, 2002, p. 102), which allow for the conceptualization of an audience as several, possibly unknown parties, a "dynamic social interaction that often involves multiple and conflicting reader roles" (Reiff, 2002, p. 110). I now consider audience profiling somewhat counterproductive to what I wanted to achieve as I meant for students to become aware of all the audiences there are to their texts rather than focusing them on a single one. It might have been helpful to students if I had given them the chance to compose several versions of the same text raising the complexity of the audience to be addressed with each step, slowly accumulating the necessity to handle different audiences at the same time.

Finally, I did not anticipate that some students would have trouble completing the assignment due to insufficient reading skills, a notion which I infer from their evaluation of the chosen text as "bad" and "incomprehensible." I am more aware now that genuine academic literacy comprises reading and writing skills in equal measure (see Odom, 2013, p. 1). However, as Robert Scholes (2002) argues, "we...fail to teach close reading" (p. 166) in academia. I find that this is particularly true for literary studies, where students' reading skills concerning academic texts are taken for granted by both lecturers and students, while their literary reading skills are perpetually trained. This might be due to the fact that teachers in literary studies barely "see" (Scholes, 2002, p. 166) how well students do (not) read academic texts while being regularly confronted with students' possibly flawed readings of literary texts. If I had performed a reading-to-write informed sample reading of an academic text with my students, I might have facilitated their processing of the appointed reading.

\section{Conclusion and Outlook}

It took many months and the professional transformation into a writing instructor for me to return to teaching audience awareness. These days I teach it in a small, introductory academic writing course for students from all disciplines at the university's writing center and, I hope, in a more successful manner than before. I am in a privileged position now and at liberty to spend several sessions on writing situations, to properly scaffold my writing assignments, to provide step-bystep summary writing trainings, to discuss the advantages and disadvantages of audience profiling in detail, and to perform sample readings. I have also greatly benefited from the writing center's theoretical and practical expertise and take fewer aspects for granted when it comes to what students may (not) know about or be able to do with academic reading and writing.

Based on my own experience and development, I still consider teaching audience awareness in discipline-specific courses a challenging endeavor. While my teaching experience suggests that it could be favorable to approach audiences as real-life addressees in teaching, writing research confirms that writing for an audience remains a difficult skill to teach that can possibly neither "be taught directly" nor "very quickly" (Park, 1982, p. 256). In my experience, teaching audience awareness also tends to lag far behind seemingly more pressing concerns among faculty, such as teaching appropriate source use or structure, in its perceived significance for writers' development in discipline-specific courses. However, audience awareness is a crucial skill to learn for student writers in academic environments which have increasingly regarded writing as a significant "social act," a situated communicative practice, and in which successful 
audience address is considered a "constitutive element... of a disciplinary context" (Hyland, 2001 , p. 549). Therefore, I would like to advocate the integration of writing assignments on audience awareness by lecturers in the disciplines. My students might have been frustrated with the assignment, but it raised their awareness for the importance of thinking about audiences when writing in relation to their discipline and beyond it, i.e. their prospective professional environments. I hope that my retrospective analysis might function as a shortcut for lecturers who are motivated to venture into teaching audience awareness and help them to avoid some dead ends.

Without much knowledge about the discourse on audiences in academic writing and with limited experience in teaching writing skills, audience awareness might seem a particularly challenging topic to teach for lecturers in the disciplines, though. To foster the integration of teaching audience awareness in discipline-specific courses it may, therefore, be beneficial to cultivate collaborations between faculty and writing instructors. Having cooperated as a writing instructor with several lecturers from different disciplines in discipline-specific contexts, I now consider this approach far superior to any isolated attempt to teach students audience awareness. Lecturers are uniquely positioned to support their students in learning audience awareness in their double role as academic teachers and members of the respective discourse community, which provides them with an often implicit but for students (and writing instructors) valuable wealth of knowledge about audience expectations in the respective field, and elaborate strategies how to cater to them in writing. Writing instructors contribute theoretical and practical know-how about how to address the challenges of effective audience awareness trainings, as illustrated above, and awareness of the necessity to explicate lecturers' tacit, discipline-specific writing expertise in a classroom. A consolidation of these proficiencies seems to be the bestpractice approach we have to teaching audience awareness without having to turn lecturers into writing instructors and writing instructors into lecturers. If universities manage to capitalize on the combined strengths of their teaching personnel, they will enable teachers and students to tackle even complex writing skills, such as audience address, in discipline-specific courses. 


\section{References}

Beaufort, A. (2007). College writing and beyond: A new framework for university instruction. Utah State University Press.

Casey, B., Casey, N., Calvert, B., French, L., \& Lewis, J. (2002). Television studies: The key concepts. Routledge.

Cooper, M. M. (1986). The ecology of writing. College English, 48(4), 364-375. https://doi.org/10.2307/377264

Ede, L. (1984). An introduction to research. College Composition and Communication, 35(2), 140-154. https://doi.org/10.2307/358092

Ede, L., \& Lunsford, A. (1984). Audiences addressed/Audiences invoked: The role of audience composition theory and pedagogy. College Composition and Communication, 35(2), 155-171. https://doi.org/10.2307/358093

Hyland, K. (2001). Bringing in the reader: Addressee features in academic articles. Written Communication, 18(4), 549-575. https://doi.org/10.1177/0741088301018004005

Johnson-Sheehan, R., \& Paine, C. (2010). Writing today. Longman.

Odom, M. L. (2013). Not just for writing anymore: What WAC can teach us about reading to learn. Across the Disciplines: A Journal of Language, Learning and Academic Writing, 10(4), 1-14. https://wac.colostate.edu/docs/atd/reading/odom.pdf

Park, D. B. (1982). The meaning of "audience." College English, 44(3), 247-257. https://doi.org/10.2307/377012

Pope-Ruark, R. (2011). Know thy audience: Helping students engage a threshold concept using audience-based pedagogy. International Journal for the Scholarship of Teaching and Learning, 5(1), 1-16. https://doi.org/10.20429/ijsotl.2011.050106

Purdue OWL (2015). Elements of rhetorical situations. Purdue Online Writing Lab. https://owl.purdue.edu/owl/general writing/academic writing/rhetorical situation/elem ents of rhetorical situations.html.

Reiff, M. J. (2002). Teaching audience post-process: Recognizing the complexity of audiences in disciplinary contexts. The WAC Journal, 13, 100-111. https://wac.colostate.edu/journal/vol13/reiff.pdf

Scholes, R. (2002). The transition to college reading. Pedagogy, 2(2), 165-172. https://doi.org/10.1215/15314200-2-2-165

UMUC (n.d.). Prewriting: Targeting your audience. University of Maryland Global Campus Online Guide to Writing Research. https://coursedev.umuc.edu/WRTG999A/chapter2/ch2-04.html 


\section{Appendix 1: Slides Used in the Classroom}

\section{Slide 1}

\section{The Rhetorical Situation}

- "This term refers to any set of circumstances that involves at least one person using some sort of communication to modify the perspective of at least one other person." (Purdue OWL 2015: $\mathrm{n}$. pag.)

- "Each individual rhetorical situation shares five basic elements with all other rhetorical situations:

1. A text (i.e., an actual instance or piece of communication)

2. An author (i.e., someone who uses communication)

3. An audience (i.e., a recipient of communication)

4. Purposes (i.e., the varied reasons both authors and audiences communicate)

5. A setting (i.e., the time, place, and environment surrounding a moment of communication)." (Purdue OWL 2015: n. pag.)

\section{Slide 2}

\section{Author Purposes}

(Johnson-Sheehan and Paine $2010: 17$ )

\begin{tabular}{|c|c|}
\hline Informative & Persuasive \\
\hline to inform & to persuade \\
\hline to describe & to convince \\
\hline to define & to influence \\
\hline to review & to argue \\
\hline to notify & to recommend \\
\hline to instruct & to change \\
\hline to advise & to advocate \\
\hline to announce & to urge \\
\hline to explain & to defend \\
\hline to demonstrate & to justify \\
\hline to illustrate & to support \\
\hline
\end{tabular}

\section{Slide 3}

\section{Targeting Audiences}

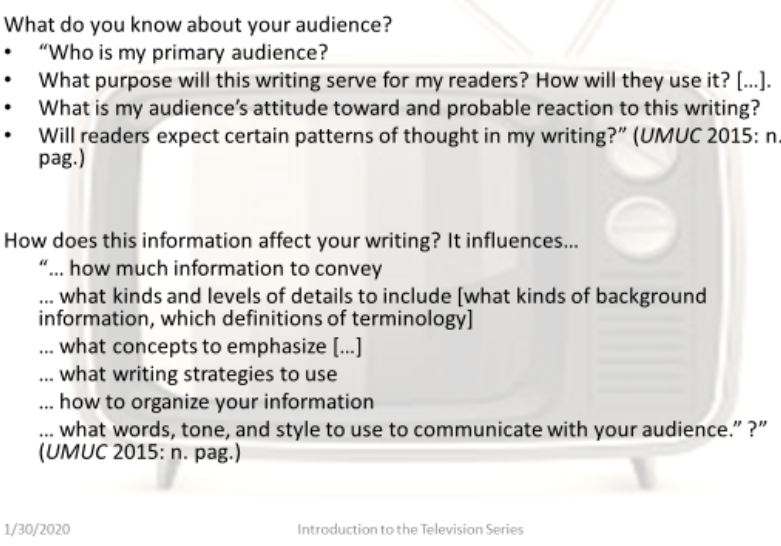




\section{Appendix 2: Writing Assignment}

Option 1: You are writing a term paper about the The Sopranos's revival of traditional elements of the crime drama genre on television. You want to start your theory chapter with an explanation of the general development of television drama series in the course of the twentieth century in order to later on locate The Sopranos in the generic tradition. Provide a summary of 200-300 words of the key theses of the text Drama (Casey et al. 2002: 71-76) for your term paper's theory chapter. Before you start writing try to clarify for yourself the purpose(s) of your text as well as your audience's profile and write your text accordingly.

Option 2: You are doing your first internship in a secondary school. On Mondays your first lesson is English in the eighth grade and you would like to teach television drama series in the next lesson. Anyhow, the best text on television drama you could find is much too long to discuss in a forty-five-minute lesson. Accordingly, you decide to write a summary of the text's key theses for your pupils. Provide a summary of 200-300 words of the key theses of the text Drama (Casey et al. 2002: 71-76) for your lesson. Before you start writing try to clarify for yourself the purpose(s) of your text as well as your audience's profile and write your text accordingly.

Option 3: You are doing your first internship in a famous publishing house. In your second week there, your boss asks a favor of you. He needs to meet with the author of a newly published book on television studies but has not yet had the time to read the author's book. He asks you to write a summary of the key theses of the book's chapter on Drama for him so that he will appear well informed in the meeting. He admits that he has never engaged with the topic of television studies and has absolutely no idea about television drama. Provide a summary of 200-300 words of the key theses of the text Drama (Casey et al. 2002: 71-76) for your boss in the publishing house. Before you start writing try to clarify for yourself the purpose(s) of your text as well as your audience's profile and write your text accordingly. 